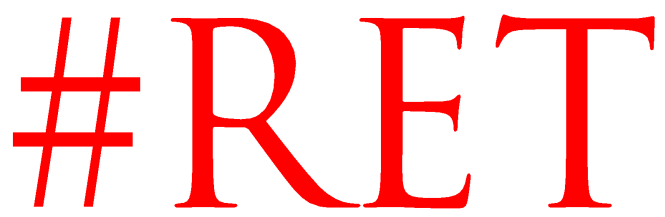

Revista Española de la Transparencia

Núm. 10. Primer Semestre 2020

ISSN 2444-2607. Págs. 97-111

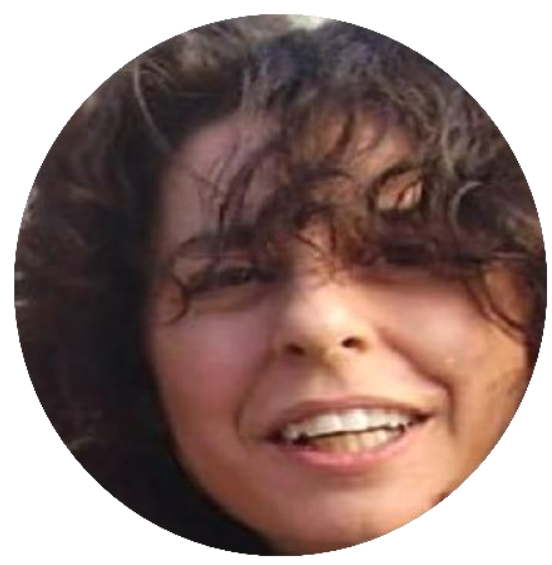

Eva Gamero Ruiz1

Junta de Andalucía. España

\title{
Participación ciudadana en la evaluación ambiental de ilícitos urbanísticos masivos
}

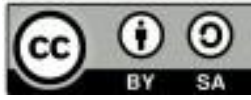

RECIBIDO: 6 de octubre de 2019 ACEPTADO: 17 de febrero de 2020

RESUMEN: El objeto del presente estudio es analizar la relación entre tres fenómenos jurídicos aparentemente inconexos, pero que la realidad más próxima pone en relación, confiriendo a la participación pública un alcance insospechado.

Audiencia de la colectividad a través de la consulta pública, evaluación ambiental y tratamiento legal de irregularidades masivas respecto de las que han prescrito las acciones de disciplina urbanística, son fenómenos destinados a enlazarse si tenemos en cuenta que las diferentes Comunidades Autónomas en España han acometido el reconocimiento más o menos definitivo de los ilícitos urbanísticos que vienen asolando su territorio y su paisaje desde hace varias décadas.

PALABRAS CLAVE: Participación pública, evaluación ambiental, irregularidades urbanisticas masivas, grupos de interés.

CONTENIDOS: 1. La consulta pública en el proceso de reconocimiento legal de irregularidades urbanísticas prescritas. - 2. Transparencia en la información sobre ilegalidades urbanísticas y en la necesidad de ejercer eficazmente la disciplina urbanística. - 3. La acción pública como mecanismo de salvaguarda de la legalidad urbanística. - Bibliografía.

\footnotetext{
${ }^{1}$ Técnico de Administración Local e Inspectora de Ordenación del Territorio, Urbanismo y Vivienda de la Junta de Andalucía.
} 


\section{Eva Gamero Ruiz}

\section{Citizen participation in the environmental assessment of territorial} illegalities

ABSTRACT: Citizen participation through public consultation, environmental assessment and legal treatment of massive irregularities with respect to those that have prescribed the actions of discipline, are phenomena destined to be linked if we consider that the time has come for the various regions of Spain are carrying out the more or less definitive regularization of territorial illegalities that have been devastating their territory and their landscape for several decades.

KEYWORDS: Public participation, environmental assessment, territorial illegalities, lobbies. 


\section{Participación ciudadana en la evaluación ambiental ...}

\section{LA CONSULTA PÚBLICA EN EL PROCESO DE RECONOCIMIENTO LEGAL DE IRREGULARIDADES URBANISTICAS PRESCRITAS.}

El Plan urbanístico, expresión normativa de la potestad de planeamiento, es por excelencia el instrumento del que disponen las Administraciones para configurar la realidad urbanística y territorial, debiendo recordarse , además, que el artículo 22.7 del Real Decreto Legislativo 7/2015, de 30 de octubre, por el que se aprueba el texto refundido estatal de la Ley de Suelo y Rehabilitación Urbana, TRLS, apura al máximo el carácter instrumental del planeamiento disponiendo que "La legislación sobre ordenación territorial y urbanistica establecerá en qué casos el impacto de una actuación de urbanización obliga a ejercer de forma plena la potestad de ordenación del municipio o del ámbito territorial superior en que se integre, por trascender del concreto ámbito de la actuación los efectos significativos que genera la misma en el medio ambiente". Es decir, en base a los principios de desarrollo territorial y urbano sostenible ${ }^{2}$, consagrado en el art. 3 del TRLS, y de no regresión ambiental ${ }^{3}$, los intentos de regularización de edificaciones ilegales, aún en los casos en que hayan transcurrido los plazos para ejercer las potestades de disciplina urbanística, han de someterse a evaluación ambiental, y cuando la entidad de las irregularidades lo demande, ha de realizarse una verdadera evaluación ambiental estratégica del plan urbanístico que integre dichas edificaciones irregulares, ejercitando en forma plena la potestad de planeamiento.

El ejercicio de esta potestad pública indisponible, cuya dirección y control del proceso urbanístico corresponde a la Administración y no a los particulares, art. 4.2 a) TRLS, deberá en todo caso garantizar tanto la participación de la comunidad en las plusvalías generadas por la acción de los entes públicos (art. 4.2 b) TRLS) como el derecho a la información de los ciudadanos y de las entidades representativas de los intereses afectados por los procesos urbanisticos, asi como la participación ciudadana en la ordenación y gestión urbanisticas (art. 4.2 c) TRLS)

Uno de los trámites esenciales de todo plan urbanistico es justamente la apertura de consultas a los interesados, que hace efectiva la participación ciudadana en un

2 Con arreglo al citado art. 3.1 TRLS: Las políticas públicas relativas a la regulación, ordenación, ocupación, transformación y uso del suelo tienen como fin común la utilización de este recurso conforme al interés general y según el principio de desarrollo sostenible...2. En virtud del principio de desarrollo sostenible, las políticas a que se refiere el apartado anterior deben propiciar el uso racional de los recursos naturales armonizando los requerimientos de la economía, el empleo, la cohesión social, la igualdad de trato y de oportunidades, la salud y la seguridad de las personas y la protección del medio ambiente.

3 Principio de no regresión ambiental que la jurisprudencia más reciente ha consolidado como un principio general del derecho ( Cfr. STS 10 julio 2012, ROJ: STS 5538/2012, STS de 30 de septiembre de 2011 (Casación 1294/2008); de 29 de marzo de 2012 (Casación 3425/2009); 10 de julio de 2012 (Casación 2483/2009) y 29 de noviembre de 2012 (Casación 6440/2010) o de 14 octubre 2014 (Casación 2488/2012); así como la Sentencia del Tribunal Constitucional 134/2019, de 13 de noviembre (BOE núm. 304, de 19 de diciembre de 2019). 


\section{Eva Gamero Ruiz}

momento tan crucial para la gestación de un plan urbanístico como es el de su evaluación ambiental.

Pero ocurre que el proceso de ocupación ilegal del territorio por las edificaciones es un proceso puramente fáctico y plenamente confiscatorio de esta consulta pública previa. La fase de participación pública corre entonces el riesgo de convertirse en un instrumento de justificación de las irregularidades masivas, en la medida que adquieren únicamente voz quienes han cometido dichas irregularidades o se convierten a posteriori en titulares de las construcciones ilegales, como grupos de presión o lobbies no siempre formalizados pero visibles ${ }^{4}$.

Por ello, debe ser objeto de análisis las contradicciones a que pueden dar lugar un entendimiento incondicional de la consulta pública, lo que plantea un problema que no es posible resolver sin una reflexión previa sobre la disponibilidad/ indisponibilidad de los bienes juridicos en juego y sobre las cautelas de las que debe rodearse la evaluación ambiental de actuaciones urbanísticas, siempre desde la perspectiva de los principios de legalidad, transparencia y protección significativa de los intereses medioambientales.

Las operaciones de reconocimiento legal de las edificaciones ilegales (sea en forma individual, a través de declaraciones de asimilación a fuera de ordenación, o colectiva, a través de Planes urbanísticos especiales o generales) que han afectado gravemente a recursos públicos escasos y valiosos, como el agua, el suelo no transformado 5 el paisaje, no pueden estar condicionadas o monopolizadas por la opinión de los titulares de dichas edificaciones. Por ello, es necesario garantizar la transparencia en el proceso, incorporando algún tipo de aviso o informe sobre la ilegalidad de la edificación. El evaluador ambiental (del proyecto individual o del plan o programa) debe incorporar como parte de su lex artis la distinción de intereses en juego, identificando a los responsables de los impactos condicionantes del proceso de transformación evaluado.

4 Señala ARAGUÁS GALCERÁ, I. "La participación ciudadana en la elaboración de disposiciones generales: estado de la cuestión y perspectivas de futuro tras la aprobación de la Ley 39/2015, de 1 de octubre, de procedimiento administrativo común de las administraciones públicas", en Revista Andaluza de Administración Pública, núm. 96, septiembre-diciembre 2016, p. 91, que el decreciente interés de los ciudadanos en las políticas públicas suele coincidir con el aumento de la actividad de diferentes grupos de presión, que en nuestro país llevan a cabo su actividad prácticamente al margen de cualquier regulación. Por ello, aboga junto con otros autores (PONCE SOLÉ, J. Negociación de normas y lobbies, Aranzadi, Navarra, 2015 y DEL OLMO ALONSO, J. 1998 "El procedimiento de elaboración negociada de reglamentos en la legislación de los Estados Unidos", en RVAP núm. 52), por un sistema de participación caracterizado por la transacción entre los grupos de interés y los poderes públicos, como ocurre en otros países, como Alemania o Estados Unidos. Sobre recomendaciones para mejorar la participación en la producción normativa y propuestas de buenas prácticas que puedan servir de ejemplo, vid. SIERRA RODRÍGUEZ, J. La participación en la elaboración de normas en la Administración General del Estado. Ministerio de la Presidencia, Relaciones con las Cortes e Igualdad. Centro de Estudios Políticos y Constitucionales. Madrid, 2019, pp. 215-217.

5 La Exposición de Motivos de la Ley de Suelo 8/2007, de 28 mayo, califica el suelo no sólo como un recurso económico, sino como recurso natural, escaso y no renovable. Estimando los expertos que para formar $1 \mathrm{~mm}$ de suelo se requieren entre 100 y 1000 años, de ahí que el suelo sea considerado recurso natural no renovable a escala de la vida humana. 


\section{Participación ciudadana en la evaluación ambiental ...}

Entendemos que la pauta a seguir es la evaluación de proyectos anulados judicialmente, prevista en la Disposición adicional decimosexta de la Ley 21/2013, de Evaluación Ambiental, introducida por la Ley 9/2018, de 5 de diciembre, rubricada "Evaluaciones en ejecución de sentencia firme". Pensada para solventar el problema suscitado por la anulación de proyectos urbanísticos que no han sido correctamente evaluados ambientalmente -situación frecuente en los repertorios jurisprudenciales ${ }^{6}$ - con la consecuencia de que debe efectuarse la evaluación de los posibles efectos significativos sobre el medio ambiente de un proyecto parcial o totalmente realizado, la solución legislativa ha consistido en reconocer la necesidad de adicionar al procedimiento general de evaluación ciertas especialidades.

Traduciéndose éstas en la sustitución de los principios de acción preventiva y cautelar por el de compensación y reversión de impactos causados, y en la prevalencia de los análisis prospectivos o retrospectivos teniendo en cuenta la realidad física existente. Esta filosofía es plenamente aplicable a estos supuestos de incorporación ex novo por el planeamiento de una realidad urbanistica irregular preexistente y consumada.

\section{2.- TRANSPARENCIA EN LA INFORMACIÓN SOBRE ILEGALIDADES URBANÍSTICAS $Y$ EN LA NECESIDAD DE EJERCER EFICAZMENTE LA DISCIPLINA URBANISTICA.}

Entendemos necesario fomentar la cultura de la transparencia respecto a las ilegalidades urbanísticas, de forma que tanto la publicidad activa ${ }^{7}$ como la faceta pasiva o derecho de acceso a la información mediante solicitud ${ }^{8}$, deben facilitar una información real sobre la situación urbanistica de terrenos y construcciones y sobre las medidas de disciplina urbanística procedentes. Esta información debe ser considerada "información pública", por tratarse la disciplina urbanística de una función pública no susceptible de transacción.

Confluyendo varios grupos normativos en esta materia, la llamada "información urbanística" se incluye sin grandes esfuerzos interpretativos en el concepto más

6 "Más de 90 los planes de urbanismo anulados judicialmente por no realizar la evaluación ambiental estratégica", RAMOS MEDRANO, J.A., Actualidad Jurídica Ambiental, n 73, noviembre 2017. pp 16-21.

$7 \mathrm{Si}$ bien en España la información urbanística se ha sometido tradicionalmente a mecanismos de publicidad activa, lo cierto es que las posibilidades de digitalización de los planes urbanísticos y de la propia Administración electrónica permiten en la actualidad una auténtica publicidad activa, que, como señala GUICHOT, E, "Ejercicio del derecho de acceso a la información pública y régimen de impugnaciones" en VV:AA La Ley 19/2013, de transparencia, acceso a la información y buen gobierno. Una perspectiva académica. CEPC, 2014.p 22, impone a la Administración competente la obligación de poner la información a disposición de todos motu propio, sin esperar el planteamiento de solicitudes individuales.

8 Proponiendo interesantes medidas especificas para hacer efectivo este derecho y el diálogo entre ciudadanos y Administración pública, IBARZ MORET, A. y RUBIO NUÑEZ, R. , La Participación en la Administración General del Estado a través de medios digitales. Ministerio de la Presidencia, Relaciones con las Cortes e Igualdad. Centro de Estudios Politicos y Constitucionales. Madrid, 2019, pp 191-194. 


\section{Eva Gamero Ruiz}

amplio de "información ambiental", sin perjuicio de las especificidades de la normativa urbanística y del carácter supletorio de la Ley estatal de Transparencia, respecto de la información ambiental (Disposición adicional primera Ley 19/2013, de 9 de diciembre, de transparencia, acceso a la información pública y buen gobierno).

En efecto, la amplitud de la definición de "información ambiental" contenida en la Ley 27/2006, de 18 de julio, reguladora de los derechos de acceso a la información, de participación pública y de acceso a la justicia en materia de medio ambiente (art. 1), tal y como han señalado los tribunales (v. gr. STSJ Canarias 402/2017, de 18 de noviembre) permite incluir como tal información de naturaleza propiamente urbanística, en especial, cuando se trata de usos en el suelo no urbanizable, pero incluso también para suelo transformado urbanísticamente ${ }^{9}$. Así, la definición de "información ambiental" incluye además de la situación de los elementos ambientales, y los factores naturales o antrópicos que inciden sobre ellos, las medidas, como políticas, planes, programas, acuerdos o actos que afecten a las dos categorias precedentes, los informes sobre la ejecución de la legislación medioambiental, los análisis económicos utilizados para la toma de decisiones y el estado de la salud y seguridad de las personas. Estas medidas incluyen todas las formas de ejercicio de la actividad administrativa (Orden del Ministerio de Medio Ambiente AAA/1601/2012, de 26 de junio, por la que se dictan instrucciones sobre la aplicación en el Departamento de la Ley 27/2006, de 18 de julio, por la que se regulan los derechos de acceso a la información, de participación pública y de acceso a la justicia en materia de medio ambiente (BOE núm.172, de 19 de julio de 2012).

Por ejemplo, peticiones de información sobre medidas de disciplina urbanística adoptadas respecto de un inmueble, licencias municipales o reconocimientos de las situaciones ilegales respecto de las que hayan transcurrido los plazos para su demolición (conocidas en Andalucia como situaciones de asimilación a la de fuera de ordenación $\left.^{10}\right)$, pueden considerarse a estos efectos peticiones de información pública medioambiental.

\footnotetext{
9 Así lo entienden la jurisprudencia comunitaria, STJUE (Gran Sala), de 14 de febrero de 2012, asunto C-204/O9, o STJUE 17 junio 1998, Asunto 321/96. Meclenburg, y los Tribunales españoles, como botón de muestra, la STSJ Castilla La Mancha 239/2017, de 20 de octubre, recurso de apelación 148/2016, señala que las licencias de actividad y las medidas correctoras de impactos ambientales, ruido en este caso, constituye información urbanístico-ambiental. Para estudio de jurisprudencia en aplicación del Convenio de Aarhus, vid. BRUFAO CURIEL, P." Transparencia administrativa y medio ambiente: contenido y aplicación práctica del Derecho de acceso a la información reconocido por el Convenio de Aarhus, pp 119-122 en La aplicación de la Transparencia: educación y Universidad, Justicia, Medioambiente y contratación. Coord. SERRALLO MAíLLO, I. Universidad Complutense de Madrid y ACREDITRA. 2018.

10 Sobre la naturaleza y régimen jurídico de las situaciones "asimiladas a fuera de ordenación", JORDANO FRAGA, J. Coord. El urbanismo de la crisis. La regulación de edificaciones ilegales y el régimen de fuera de ordenación. Ed. TECNOS., 2015, pp. 79-89; TOLEDO PICAZO, A. Licencias y disciplina urbanistica. Bosch, 2013, pp 440-443
} 


\section{Participación ciudadana en la evaluación ambiental ...}

Respecto a las autoridades obligadas a prestar información urbanístico-ambiental, en principio quedan fuera las autoridades legislativas y judiciales, pero sólo cuando desempeñen tales funciones (art. 2.4.3 Ley 27/2006), de forma que esta previsión no alcanza a los Ministros y Consejeros cuando elaboran y adoptan disposiciones normativas de rango inferior a la ley ( STJUE 18/7/2013 C-515/11, Deutsche Umwelthilfe eV); naturaleza que ostentan, por ejemplo, los Planes de Ordenación Territorial y los Planes Urbanísticos ${ }^{11}$, incluyendo aquellos Planes especiales que tengan por objeto la adecuación territorial y ambiental de las edificaciones irregulares.

En cuanto a los límites de acceso, muchos de los casos que la normativa medioambiental considera excepciones al acceso son tratados como supuestos de inadmisión en la normativa general. Además, la Ley 19/2013, de Transparencia, contiene una mayor amplitud en los límites del derecho de acceso que la Ley 27/2006, de acceso a la información en materia de medio ambiente, en supuestos de concurrencia con otros bienes jurídicamente protegidos (por ejemplo, el referido a la política económica y monetaria, que no está previsto en la norma ambiental), pero en la norma sobre información ambiental se contempla expresamente como límite del acceso a la información ambiental la protección del medio ambiente al que se refiere la información solicitada (art. 13.2 h) Ley 27/2006). La finalidad de esta previsión no es otra que la de evitar un uso fraudulento de la información solicitada, si con ella se pretendiese un fin contrario a la preservación del medio ambiente. Conforme interpreta la citada Orden AAA/1601/2012, de 26 de junio, se ha de realizar una interpretación restrictiva de esta limitación, ponderando caso por caso el interés público atendido con la divulgación con el interés que demande su denegación ${ }^{12}$.

Desde el punto de vista de la publicidad activa, la regulación general tiene carácter de mínimo (art. 5.2 Ley 19/2013, de Transparencia), de forma que será de aplicación preferente la Ley $27 / 2006$ y supletoriamente, la Ley 19/2013, en cuestiones no contempladas expresamente por la norma especial (por ejemplo, intervención de terceros en el procedimiento), siempre considerando que se trata de regímenes complementarios y no excluyentes, de forma que los particulares pueden ampararse en ambas regulaciones para no ver mermados sus derechos de acceso.

11 La naturaleza normativa de los Planes territoriales y urbanísticos está siendo actualmente cuestionada por cierta doctrina, que aboga por una modificación legal que disponga expresamente su carácter de actos administrativos generales, o por bien por la atribución de una doble naturaleza, que sustituya el carácter puramente normativo-reglamentario de los Planes. Y ello con el fin de evitar los efectos "ex tunc" de las declaraciones judiciales de nulidad de los planes, así como por la imposibilidad de convalidar o declarar nulidad parcial en caso de concurrencia de causa de nulidad de pleno derecho del plan. Vid. AGUADO GONZÁLEZ, J. Coordinador. Nulidad de Planeamiento y ejecución de sentencias. Bosch, 2018, pp.231-245.

12 Así, la sentencia del Tribunal de Justicia de la Unión Europea en el asunto C 552/07, señaló que no cabe invocar una reserva por protección de orden público u otros intereses del Estado para denegar la solicitud de información sobre ubicación exacta, mediante coordenadas geográficas, del lugar concreto donde se realice la liberación de organismos modificados genéticamente, debiendo prevalecer las exigencias de transparencia derivadas de las Directivas comunitarias. 


\section{Eva Gamero Ruiz}

Las dudas sobre el alcance de esta aplicación supletoria deben resolverse "pro acceso", salvo que sea en perjuicio de la protección del medio ambiente, supuesto en que debe prevalecer esta protección, tal y como señala el Dictamen 1/2017, de 20 de abril, de la Comisión de Garantía del Derecho de Acceso a la Información Pública de Cataluña.

Compartimos la opinión de FERNÁNDEZ RAMOS y de PÉREZ MONGUIÓ, en cuanto a la no aplicación a las solicitudes de información urbanística-ambiental de las excepciones o el silencio negativo de la regulación común, por el obligado cumplimiento del Convenio de Aarhus y la Directivas comunitarias, pero sí de la aplicación el recurso especial ante el Consejo de Transparencia y Buen Gobierno ${ }^{13}$.

Resulta interesante la propuesta de RAZQUÍN ${ }^{14}$, tras señalar el difícil encaje del silencio con la propia naturaleza del derecho de acceso-que exige bien el suministro de la información ambiental o bien la denegación motivada en plazoconsidera viable, en caso de silencio positivo, la exigencia del suministro de la información a través del cumplimiento de la obligación de realizar una prestación a favor del solicitante, en base al art. 29 de la Ley 29/1998, de la Jurisdicción contencioso administrativa ( STSJ Valencia 649/2012, de 5 de diciembre, recurso 824/2010). En esta línea, significamos que la falta de ejecución efectiva por una Administración autonómica de Resolución dictada en procedimiento que ordenaba la reposición de la realidad física alterada, ha sido considerada por los Tribunales como inactividad a los efectos de ser poder ser recurrida en vía contencioso administrativa, resultando compelida judicialmente la Administración a ejecutar su orden de demolición, en base al art. 29 de la citada Ley 29/1998, de la Jurisdicción contencioso administrativa (Sentencia 2274/2018, de 12 de Diciembre, de la Sala de lo Contencioso Administrativo en Granada del Tribunal Superior de Justicia de Andalucia).

A propósito del recurso especial ante una autoridad independiente de Transparencia, siendo la información urbanística/ambiental información pública, estimamos que no cabe en principio dejar de admitir tales reclamaciones en

13 FERNÁNDEZ RAMOS, S. y PÉREZ MONGUIÓ, J.M., El Derecho de Acceso a la Información Pública en España, Aranzadi, Cizur Menor, 2017, pp 65-68, entienden, por una parte, que el silencio desestimatorio sería incompatible con la exigencia de motivación de la Directiva 2003/4/CE y por otra, que la garantía de acceso al recurso especial es más acorde con la letra y el espíritu del Convenio de Aarhus. En el mismo sentido, realizando una interpretación de la normativa sobre acceso a la información pública con los criterios del art. 3.1 del Código Civil, GUICHOT REINA, E. "La competencia de las autoridades de control en materia de reclamaciones en materia de información ambiental, de reutilización y archivistica", en Revista Española de Transparencia, n. ${ }^{\circ}$ 4. Primer Semestre 2017. pp 25-28.

14 RAZQUÍN LIZARRAGA, J.A., "El acceso a la información en materia de medio ambiente en España: balance y retos de futuro". En Revista Catalana de Dret Ambiental, Vol.IX Núm. I ( 2018) , pp. 22-23. 


\section{Participación ciudadana en la evaluación ambiental ...}

aplicación de la Disposición adicional primera de la Ley 19/2013, si bien el criterio no es unánime en los órganos competentes. ${ }^{15}$

Más dudoso resulta que, solicitada información sobre la legalidad de un determinado inmueble, se desestime en base a que ello no constituye "información pública" (caso de la Resolución 282/2018, de 11 de julio, del Consejo Andaluz de Transparencia). Entendemos que si un Ayuntamiento, debiendo de ejercitar de forma obligada sus potestades de disciplina urbanística, no lo hace, y un particular acude al Consejo de Transparencia, demandando información sobre el estado de ejercicio de esta potestad debida en un caso concreto, el ciudadano no debe quedar desamparado ante el doble incumplimiento de la Administración: primero, no ejercitando debidamente sus potestades en disciplina urbanística; y segundo, no contestando la petición del demandante de información ${ }^{16}$.

Tal como ha establecido como doctrina legal el Tribunal Supremo, Sentencia 1547/2017, de 16 de octubre (Sala de lo Contencioso-Administrativo, Sección Tercera) en su FJ SEXTO: "La formulación amplia en el reconocimiento y en la regulación legal del derecho de acceso a la información obliga a interpretar de forma estricta, cuando no restrictiva, tanto las limitaciones a ese derecho que se contemplan en el art. 14.1 de la Ley 19/2013, como las causas de inadmisión de solicitudes de información que aparecen enumeradas en el artículo 18.1. sin que quepa aceptar limitaciones que supongan un menoscabo injustificado y desproporcionado del derecho de acceso a la información. Por ello, la causa de inadmisión de las solicitudes de información que se contempla en el artículo 18.1.c) de la Ley 19/2013, de 9 de diciembre, no opera cuando quien invoca tal causa de inadmisión no justifique de manera clara y suficiente que resulte necesario ese tratamiento previo o reelaboración de la información. Asimismo, la posibilidad de limitar el derecho de acceso a la información no constituye una potestad discrecional de la Administración o entidad a la que se solicita información, pues aquél es un derecho reconocido de

15 Tanto el Consejo de Transparencia y Buen Gobierno estatal y la Comisión de Transparencia y Protección de Datos de Andalucía en ocasiones inadmiten ( Resoluciones 18/8/2017 y 24/10/2017 del Consejo Estatal y Resoluciones del Consejo Andaluz de 16 febrero 2018 , 127/2019, de 23 abril ( Nijar ) 140/2018, 24 abril ( Barbate) ; y en otras entran en el fondo del asunto, ya sea desestimando ( Resoluciones 1/12/2017 y 4/12/2017 Consejo Estatal, o estimando Resoluciones del Consejo Andaluz 406/2018, 224/2018, de 6/6 (Gergal), 5/11/2018 (Arcos de la Fra.), 197/2018. de 30 de mayo, (Jimena de la Frontera), R 254/2018, de 27 junio, Alfique, RES-PA 112/2019, de 23 de abril, Mairena del Aljarafe, Sevilla. Sin embargo, la Comisión de Garantía del derecho de Acceso a la Información Pública de Cataluña se declara competente para resolver este tipo de materia (Resoluciones 211/2017, 27 junio y 325/2017, de 22 septiembre). Sobre esta cuestion, vid. GUICHOT REINA, E. "La competencia de las autoridades de control en materia de reclamaciones en materia de información ambiental, de reutilización y archivisitica", en Revista Española de Transparencia, n4, Primer Semestre 2017, p.15-22.

16 Como señalan FERNÁNDEZ RAMOS, S. y PÉREZ MONGUIÓ, J.M, ob.cit. p. 129, este problema se suscita cuando existe una norma que exige la producción de un documento que no se ha generado, en cuyo caso no puede ejercerse el derecho de acceso, beneficiándose la Administración de su propia torpeza -allegans propiam turpitudinem non liquet-, en contra de los principios generales del Derecho. 


\section{Eva Gamero Ruiz}

forma amplia y que sólo puede ser limitado en los casos y en los términos previstos en la Ley; de manera que limitación prevista en el artículo 14.1.h) de la Ley 19/2013 no opera cuando quien la invoca no justifica que facilitar la información solicitada puede suponer perjuicio para los intereses económicos y comerciales."

En cuanto al posible límite referido a que la revelación de la información sobre expedientes sancionadores urbanísticos pueda afectar negativamente al carácter confidencial de los datos personales, es interesante señalar con el prof. GUICHOT ${ }^{17}$ que el Reglamento General de Protección de Datos, Reglamento (UE) 2016/679, del Parlamento Europeo y del Consejo, de 27 abril de 2016, ya no otorga ningún régimen especial a los datos referentes a las sanciones administrativas, ni deja margen para ello al Estado, a diferencia de la Directiva de Protección de Datos que deroga. Por ello, como bien advierte GUICHOT ${ }^{18}$, el tenor del art. 15.1 de la Ley 19/2013, de Transparencia, no está acompasado ni con la normativa sobre protección de datos, ni con la vigente Ley Orgánica de Protección de Datos, por lo que las sanciones administrativas deberán seguir el régimen común de ponderación razonada en cada caso entre el interés público y los derechos de los afectados cuyos datos aparezcan en la información solicitada.

En el caso de que la información solicitada obre en poder de otra Administración, por ejemplo, si esta misma información sobre medidas concretas de disciplina urbanística se solicita a la Comunidad Autónoma, entendemos que ésta deberá remitir la solicitud al Ayuntamiento competente, con requerimiento de ejercicio de competencias en su caso, informando al solicitante (ex art 14.1 de la Ley 40/2015, de 1 de octubre, y arts. 18.2 y 19.1 Ley 19/2013, de Transparencia ${ }^{19}$ ). Resulta alentador que por parte del Defensor del Pueblo se sucedan las sugerencias instando a las Administraciones al ejercicio de actuaciones de inspección para facilitar las informaciones ambientales o urbanísticas solicitadas ${ }^{20}$.

17 GUICHOT REINA, E., "El acceso a los datos referidos a expedientes sancionadores o disciplinarios a la luz de la nueva normativa sobre protección de datos", en Revista Española de la Transparencia, n. ${ }^{\circ}$ 6. Primer Semestre 2018, p. 66

\section{GUICHOT REINA, E., 2018 ob.cit. p.69}

19 Recuerdan FERNÁNDEZ RAMOS, S. y PÉREZ MONGUIÓ, J.M, ob.cit. p. 257 que el modo de proceder, de acuerdo con la Ley 19/2013, de Transparencia, dependerá de si la autoridad conoce o no el sujeto en cuyo poder obra la información que se le pide, en el primer caso debe remitir la solicitud al sujeto competente, informando de esta circunstancia al solicitante (art. 19.2) y en el segundo inadmitirá la solicitud por esta causa, si bien indicando el órgano que a su juicio es competente para conocer de la solicitud ( art. 18.2)

20 Resoluciones del Defensor del Pueblo Andaluz instando a numerosos Ayuntamientos andaluces para el ejercicio de las potestades municipales de disciplina ambiental. Por ejemplo, la queja 17/5294 dirigida a Ayuntamiento de Écija (Sevilla, o para el ejercicio de las potestades de disciplina urbanística: queja 15/4762 dirigida a Ayuntamiento de Ogijares (Granada), queja 16/2513 dirigida a Ayuntamiento de Tomares (Sevilla), queja 17/6009 dirigida a Ayuntamiento de Lora del Río (Sevilla), queja 17/2072 dirigida a Ayuntamiento de Sevilla, queja 16/5606 dirigida a Ayuntamiento de Almonte (Huelva), queja 16/5703 dirigida a Ayuntamiento de Alcaucin (Málaga), queja 17/4750 dirigida a Ayuntamiento de Benalmádena (Málaga), queja 15/1415 dirigida a Ayuntamiento de Valle de Abdalajís (Málaga), queja 16/1230 dirigida a Ayuntamiento de Carboneras (Almería), queja 16/o918 dirigida a Presidencia 
En materia ambiental y urbanistica, considerando el relevante valor probatorio de que gozan las actas e informes técnicos de los Inspectores, debe recordarse que las actas de inspección no son documentos "inconclusos" (STS 17/2/2004, casación núm. 3557/2000) ni mera información "auxiliar" o " de apoyo"21 y no se puede confundir un borrador o "informe inconcluso" con un expediente inconcluso, en el que ya figuran los informes "conclusos", por lo que, sin perjuicio de que el expediente pueda completarse con otros informes posteriores, debe facilitarse información sobre los documentos obrantes en el expediente que, siendo separables, estuvieren conclusos ( STS 29/11/2011, recurso casación 2071/2008). En este sentido, el Defensor del Pueblo (Sugerencia 11/3/2015, queja 14011733) ha entendido que los informes técnicos preparatorios de la resolución de fondo no son meras comunicaciones internas, y, por tanto, deben ser suministrados al solicitante.

Asimismo, y dada la especialidad en la tramitación de los instrumentos de planeamiento, que cuentan con una aprobación provisional previa a la definitiva, hay que aclarar que estas aprobaciones provisionales tampoco puedan ser consideradas documentos "inconclusos", como recuerda el Tribunal Supremo, Sentencias de 28 de octubre de 2003 y de 5 abril 2006 referidas a Planes de Ordenación de Recursos Naturales en tramitación ${ }^{22}$; así como la Resolución

de la Entidad Local Autónoma de Ventas de Zafarraya (Granada), queja 15/2484 dirigida a Ayuntamiento de Vejer de la Frontera (Cádiz), queja 16/3806 dirigida a Ayuntamiento de Morón de la Frontera (Sevilla), queja 16/5342 dirigida a Ayuntamiento de Roquetas de Mar (Almería) o Resolución del Defensor del Pueblo Andaluz formulada en la quejas 15/0822 y 17/2018 dirigidas a Ayuntamiento de Marbella para el debido ejercicio de las potestades municipales de disciplina urbanística. Así como la Sugerencia Defensor del Pueblo estatal de 6 mayo 2016, sobre zonas acústicamente saturadas, queja 15012737.

21 BLANES CLIMENT, M. A. (2015):"¿Qué es «información auxiliar o de apoyo» y «reelaborar»?" https://miguelangelblanes.com//(acceso 15/01/2020) señala, a propósito de la interpretación realizada por el Consejo de Transparencia y Buen Gobierno (CTBG), publicada en su página web con fecha 19 de noviembre 2015, sobre diversas cuestiones de la Ley 19/2013, que el concepto que proporciona de "información preparatoria" de la actividad del órgano o entidad que recibe la solicitud es excesivamente amplio e indeterminado. En realidad, toda la documentación que integra un expediente es "información preparatoria" de la resolución administrativa, a la vista del concepto de expediente administrativo recogido en el artículo 70.1 de la Ley 39/2015, de 1 de octubre, del Procedimiento Administrativo Común de las Administraciones Públicas "Se entiende por expediente administrativo el conjunto ordenado de documentos y actuaciones que sirven de antecedente y fundamento a la resolución administrativa, asi como las diligencias encaminadas a ejecutarla". Sobre esta cuestión, concluye FERNÁNDEZ RAMOS, S. que puede afirmarse de modo categórico que la información pública objeto de acceso de acuerdo con la LTBG no se limita a aquélla contenida en los expedientes administrativos. No obstante, no puede negarse que la noción de carácter auxiliar y de apoyo contenida en la LTBG, y que constituye causa de inadmisión, ha sido ampliada por la LPAC, pues parece poco sostenible entender que la legislación básica contemple nociones diversas de información de carácter auxiliar y de apoyo, en "Información de carácter auxiliar o de apoyo: ¿vuelta a la exigencia de que la información conste en un expediente administrativo?", p 58 en Revista Española de Transparencia, n. ${ }^{\circ}$ 3. Segundo Semestre 2016.

22 La STS de 28 de octubre de 2003 declaró que la existencia de un plan en tramitación no obsta para que pueda facilitarse información sobre las actuaciones ya realizadas en el curso del mismo que sean ciertas y existentes (en concreto, en un Plan de Ordenación de los Recursos Naturales no puede considerarse «un dato o documento inconcluso» un Plan ya redactado definitivamente por la Administración, aun cuando a resultas de las alegaciones que pudieran efectuarse en período de 


\section{Eva Gamero Ruiz}

112/2019, de 23 de Abril, del Consejo de Transparencia de Andalucia, referido al incumplimiento por un Ayuntamiento de las obligaciones de publicidad activa en relación a la tramitación de un Plan Parcial, de forma que la publicidad efectiva y transparencia en la tramitación de los instrumentos urbanísticos, exige, además de los cauces tradicionales de publicación de la información pública ( Boletín Oficial de la Provincia, periódico y tablón físico), que el Ayuntamiento incorpore el anuncio de información pública en su página web y portal de transparencia.

La citada Orden AAA/1601/2012, de 26 de junio, a propósito del material en curso de elaboración o documentos inconclusos, recuerda que la aplicación de esta excepción exige que se trate de documentos en los que se está trabajando activamente $y$, por tanto, sin acabar, citando la jurisprudencia que hace una interpretación restrictiva de esta excepción ( vd. STS de 17 de febrero de 2004 (RJ 2004, 2226), en virtud de la cual no puede invocarse esta excepción para expedientes sin terminar, si las actas de reuniones, proyectos de reglamentos que estén ya enviados a órganos externos al que lo esté tramitando ( por ejemplo, planes urbanísticos enviados a otros órganos para informe o evaluación ambiental) $\mathrm{u}$ otros documentos que formen parte del expediente constituyen un verdadero soporte de información, considerado aisladamente, por estar dotados de singularidad, sustantividad y esencia propia. Tampoco podría oponerse que la información está inconclusa porque falte constatarla o compararla con otros elementos o datos.

\section{3.- LA ACCIÓN PÚBLICA COMO MECANISMO DE SALVAGUARDA DE LA LEGALIDAD URBANÍSTICA}

Un último recordatorio. Junto con este derecho de acceso a la información que debe garantizar la legislación urbanistica a todos los ciudadanos y a las entidades representativas de los intereses afectados por los procesos urbanísticos -art. $4.1 \mathrm{C}$ ) RDL 7/2015, TRL Suelo y Rehabilitación Urbana-, y además de la acción pública para la defensa de la legalidad ambiental regulada en la Ley $27 / 2006^{23}$, en materia urbanística cualquier persona ostenta acción pública para reclamar el cumplimiento de la legalidad urbanística, reconocida legalmente con carácter

\footnotetext{
información pública). En el mismo sentido, STS de 5 de abril de 2006 se remite a la del TSJ de Castilla y León de 26 de marzo de 1999, afirmando que no cabe asimilar esta excepción al procedimiento terminado del que hablaba la Ley 30/1992, de 26 de noviembre, más restrictiva. En consecuencia, declaró que el proyecto de un plan de ordenación de los recursos naturales pendiente de aprobar no podía recibir tal consideración y señaló que la denegación de la solicitud de información que había acordado la Administración no era conforme a derecho.
}

23 Sobre el acceso a la justica para la defensa de la legalidad ambiental y la habilitación legal especifica para las ONGs que representen intereses ambientales, vid. ALONSO GARCIA, M. C. "Transparencia en el ámbito del medio ambiente", pp 291-293 en el libro colectivo Transparencia y acceso a la información pública: de la teoria a la práctica. Director MARTÍN DELGADO, I. Iustel, 2019. 


\section{Participación ciudadana en la evaluación ambiental ...}

básico por el art. 5 del citado RDL 7/2015 ${ }^{24}$ y en Andalucía en el art. 6 de la Ley 7/2002, de Ordenación Urbanística de Andalucia.

Esta intervención alcanza incluso la posibilidad de reclamar el cumplimiento de resoluciones judiciales en materia urbanística, ex art. 19 d) de Ley 29/1998, reguladora de la Jurisdicción Contencioso Administrativa. Tratándose el urbanismoy en particular la disciplina urbanística- de una materia que afecta en gran medida a los Ayuntamientos, hay que añadir la llamada acción vecinal reconocida en la Ley de Bases de Régimen Local, sin perjuicio de la acción pública reconocida a los grupos ecologistas acreditados en la Ley 27/2006, de acceso a la información en materia de medio ambiente.

Los artículos 5 del RDL 7/2015, Ley de Suelo y Rehabilitación Urbana y 6 de la Ley 7/2002, de Ordenación Urbanística de Andalucía, reconocen como derechos de los ciudadanos: de una parte, el derecho a participar de forma efectiva en cualesquiera instrumentos urbanísticos y en su evaluación ambiental, y de otra, el derecho a ejercer la acción pública para hacer respetar las determinaciones de la ordenación territorial y urbanistica, asi como las decisiones resultantes de los procedimientos de evaluación ambiental de los instrumentos que las contienen y de los proyectos para su ejecución, en los términos dispuestos por su legislación reguladora" ( ley estatal), o, en palabras de la ley andaluza, la acción pública para "exigir el cumplimiento de la legalidad urbanistica, tanto en vía administrativa como en vía jurisdiccional".

Se ha planteado si la existencia de esta acción pública urbanística comporta reconocer el derecho de acceso a expedientes de restablecimiento de la legalidad urbanistica sin contar con el consentimiento del afectado, lo que se ha resuelto positivamente apelando a su distinción del procedimiento sancionador urbanístico propiamente dicho ${ }^{25}$. Además, como señala GUICHOT(2018) se ha de reconocer que sobre aquéllas materias en las que la legislación reconoce la acción pública, por tratarse de asuntos de indudable relevancia colectiva ( medio ambiente, urbanismo, patrimonio cultural, costas...), ha de prevalecer la transparencia sobre la protección de datos ${ }^{26}$.

Por tanto, la acción pública no se orienta a la tolerancia o permisión de ilegalidades urbanisticas, sino precisamente a todo lo contrario: todos los ciudadanos están legitimados para exigir, tanto en vía administrativa como jurisdiccional, el cumplimiento de la legalidad urbanística. Pues hacer ciudad, misión del urbanismo,

24 IGLESIAS GONZÁLEZ, F. " Propuestas de reformas normativas para evitar los actuales efectos de la nulidad del planeamiento urbanístico", en AGUADO GONZÁLEZ, J. Coordinador. Nulidad de Planeamiento y ejecución de sentencias. Bosch, 2018 , pp 274-278, señala que la acción pública debe reconducirse a su esencia, que es ampliar la legitimación para la observancia de la legalidad urbanistica a cualquier ciudadano.

25 FERNÁNDEZ RAMOS, S. y PÉREZ MONGUIÓ, J.M, ob.cit. p. 207 y REGO BLANCO, D. La acción popular en el Derecho Administrativo y, en especial en el Urbanistico. IAAP, Sevilla, 2005.

26 GUICHOT REINA, E. 2018 ob. cit. p. 70 


\section{Eva Gamero Ruiz}

es hacerla a la altura de los tiempos, y estos son los del triunfo de la vida urbana sostenible y en paz con la Naturaleza.

\section{BIBLIOGRAFÍA}

ALONSO GARCÍA, M. C. "Transparencia en el ámbito del medio ambiente", pp 251297 en el libro colectivo Transparencia y acceso a la información pública: de la teoría a la práctica. Director MARTíN DELGADO, I. lustel, 2019.

AGUADO GONZÁLEZ, J. Coord. Nulidad de Planeamiento y ejecución de sentencias. Bosch, 2018.

ARAGUÁS GALCERÁ, I. "La participación ciudadana en la elaboración de disposiciones generales: estado de la cuestión y perspectivas de futuro tras la aprobación de la Ley 39/2015, de 1 de octubre, de procedimiento administrativo común de las administraciones públicas", en Revista Andaluza de Administración Pública, núm. 96, septiembre-diciembre 2016.

BLANES CLIMENT, M. A. (2015):"¿Qué es «información auxiliar o de apoyo» y «reelaborar»?" https://miguelangelblanes.com/2015/11/ (acceso 15/01/2020)

BRUFAO CURIEL, P." Transparencia administrativa y medio ambiente: contenido y aplicación práctica del Derecho de acceso a la información reconocido por el Convenio de Aarhus, en La aplicación de la Transparencia: educación y Universidad, Justicia,Medioambiente y contratación. Coord. SERRALLO MAÍLLO, I. Universidad Complutense de Madrid y ACREDITRA. 2018.

DEL OLMO ALONSO, J. "El procedimiento de elaboración negociada de reglamentos en la legislación de los Estados Unidos". RVAP núm. 52. 1998.

FERNÁNDEZ RAMOS, S. "Información de carácter auxiliar o de apoyo: ¿vuelta a la exigencia de que la información conste en un expediente administrativo?", p 58 en Revista Española de Transparencia, n. ${ }^{\circ}$ 3. Segundo Semestre 2016.

FERNÁNDEZ RAMOS, S. y PÉREZ MONGUIÓ, J.M., El Derecho de Acceso a la Información Pública en España, Aranzadi, Cizur Menor, 2017.

GUICHOT REINA, E., "El acceso a los datos referidos a expedientes sancionadores o disciplinarios a la luz de la nueva normativa sobre protección de datos", en Revista Española de la Transparencia, n. ${ }^{\circ}$ 6, Primer Semestre 2018.

GUICHOT REINA, E. "La competencia de las autoridades de control en materia de reclamaciones en materia de información ambiental, de reutilización y archivistica", en Revista Española de Transparencia, n4, Primer Semestre 2017. 


\section{Participación ciudadana en la evaluación ambiental ...}

GUICHOT REINA, E, "Ejercicio del derecho de acceso a la información pública y régimen de impugnaciones" en VV.AA La Ley 19/2013, de transparencia, acceso a la información y buen gobierno. Una perspectiva académica. CEPC, 2014.

IBARZ MORET, A. y RUBIO NUÑEZ, R. La Participación en la Administración General del Estado a través de medios digitales. Ministerio de la Presidencia, Relaciones con las Cortes e Igualdad. Centro de Estudios Políticos y Constitucionales. Madrid, 2019.

IGLESIAS GONZÁLEZ, F. "Propuestas de reformas normativas para evitar los actuales efectos de la nulidad del planeamiento urbanístico", en AGUADO GONZÁLEZ, J. Coordinador. Nulidad de Planeamiento y ejecución de sentencias. Bosch, 2018.

JORDANO FRAGA, J. Coord. El urbanismo de la crisis. La regulación de edificaciones ilegales y el régimen de fuera de ordenación. TECNOS, 2015.

PONCE SOLÉ, J. Negociación de normas y lobbies, Aranzadi, Navarra, 2015.

RAMOS MEDRANO, J.A. "Más de 90 los planes de urbanismo anulados judicialmente por no realizar al evaluación ambiental estratégica", Actualidad Juridica Ambiental, nº 73, noviembre 2017.

RAZQUÍN LIZARRAGA, J.A., "El acceso a la información en materia de medio ambiente en España: balance y retos de futuro". En Revista Catalana de Dret Ambiental, Vol. IX Núm. I, 2018.

REGO BLANCO, D. La acción popular en el Derecho Administrativo y, en especial en el Urbanístico. IAAP, Sevilla, 2005.

SIERRA RODRÍGUEZ, J. La participación en la elaboración de normas en la Administración General del Estado. Ministerio de la Presidencia, Relaciones con las Cortes e Igualdad. Centro de Estudios Políticos y Constitucionales. Madrid, 2019 .

TOLEDO PICAZO, A. Licencias y disciplina urbanistica. Bosch, 2013. 
